\title{
Article \\ No-Antibiotic-Pectin-Based Treatment Differently Modified Cloaca Bacteriobiome of Male and Female Broiler Chickens
}

\author{
Svetlana B. Lysko ${ }^{1, \dagger}{ }^{,}$Olga A. Baturina ${ }^{2,+}{ }^{,}$Natalia B. Naumova ${ }^{2}$, Nadezhda A. Lescheva ${ }^{3}$, \\ Valentina I. Pleshakova ${ }^{3}$ and Marsel R. Kabilov ${ }^{2, *(D)}$ \\ 1 Siberian Scientific Research Institute of Poultry Farming - Branch of the Federal State Budget Scientific \\ Institution "Omsk Agrarian Scientific Center", 644555 Omsk, Russia; vet@sibniip.ru \\ 2 Institute of Chemical Biology and Fundamental Medicine, Siberian Branch of the Russian Academy of \\ Sciences, 630090 Novosibirsk, Russia; baturina@niboch.nsc.ru (O.A.B.); naumova@niboch.nsc.ru (N.B.N.) \\ 3 The Faculty of Veterinary Medicine, Stolypin Omsk State Agrarian University, 644008 Omsk, Russia; \\ lescheva@list.ru (N.A.L.); vi.pleshakova@omgau.org (V.I.P.) \\ * Correspondence: kabilov@niboch.nsc.ru \\ + These authors contributed equally to this work.
}

check for updates

Citation: Lysko, S.B.; Baturina, O.A.; Naumova, N.B.; Lescheva, N.A.; Pleshakova, V.I.; Kabilov, M.R. No-Antibiotic-Pectin-Based Treatment Differently Modified Cloaca Bacteriobiome of Male and Female Broiler Chickens. Agriculture 2022, 12, 24. https://doi.org/ 10.3390/agriculture12010024

Received: 29 October 2021

Accepted: 22 December 2021

Published: 27 December 2021

Publisher's Note: MDPI stays neutral with regard to jurisdictional claims in published maps and institutional affiliations.

Copyright: (C) 2021 by the authors. Licensee MDPI, Basel, Switzerland. This article is an open access article distributed under the terms and conditions of the Creative Commons Attribution (CC BY) license (https:// creativecommons.org/licenses/by/ $4.0 /)$.

\begin{abstract}
As the information about the effect of pectin prebiotics on chicken gut microbiota is scarce, by using high throughput metagenomic sequencing with Illumina Miseq we examined the cloaca bacteriobiome of male and female chickens receiving antibiotic- or pectin-containing drinking water. The bacteriobiome was dominated by two phyla (Firmicutes and Proteobacteria) and three classes (Clostridia, Bacilli and Gammaproteobacteria), with the difference displayed by the relative abundance of 42 OTUs. At the level of the major dominant OTUs, prebiotic supplementation drastically increased Enterococcus abundance (from 0 to $11 \%$ and $23 \%$ in males and females, respectively). The better feed use efficiency and growth performance of the pectin-receiving chickens implied their better health and corroborated putative beneficial role of the altered bacteriobiome, although its ecophysiological and/or pathogenic importance could not be readily inferred. Notably, the gut microbiota response to antibiotics showed more sex-related differential OTUs as compared to the pectin prebiotic (19 vs. 4), suggesting different mechanisms of the studied supplementations in shaping the gut bacteriobiome in different sexes. Therefore, we recommend targeting sex as a separate factor in interventional studies to account for sex-specific peculiarities in the microbiome response and taking into account the male/female ratio of industrial flocks prior to choosing a production technology. The studied prebiotic (pectin) can be used in developing new pre/symbiotic preparations and supplementation regimes as alternatives to antibiotics for stimulating broiler chicken production.
\end{abstract}

Keywords: 16S rRNA gene; amplicon sequencing; chicken; prebiotic; gut microbiome

\section{Introduction}

The use of poultry production to increase the food supply poses many challenges, among them the consequences resulting from the increasing numbers of birds in industrial facilities worldwide. For example, in Russia the number of chickens has increased by $11 \%$ since 2014 [1]. To enhance and sustain chicken meat production, antibiotics have been used in recent years at unprecedented rates [2], and by 2030, according to some projections, the use of antibiotics will increase by $67 \%$ [3]. Thus, industrial poultry production facilities nurture antibiotic resistance in birds' microbiota, and the genes of antibiotic resistance, together with some residual amounts of antibiotics, can get into environment with poultry litter composts [4], posing a threat to public health [5] as well as to that of other agricultural animals [6]. Thus, finding the means to decrease the use of antibiotics in poultry production is undoubtedly imperative for the near future.

By now there is no doubt that the gut microbiota of birds, similarly to that of mammals, is an important factor in intestine homeostasis and the normal metabolism of the host organism [7-9]. Exerting a significant influence on the physiology and health of birds [10,11], 
a healthy gut microbiota is important for sustaining the quantity and quality of poultry produce $[8,12,13]$. Therefore, recent years have seen a surge in research into the effects of probiotics [14-18], prebiotics [15,19-21] and synbiotics [22] on poultry microbiome and production performance. As a result, host-related factors, such as age, diet and breed, have been shown to have a large effect on poultry intestinal microbiota [23].

Prebiotics, i.e., non-digestible food ingredients utilized by intestinal microbiota [24], have been studied and supplemented broadly into broiler diets in recent years [25]. The studied prebiotics were mostly fructo-, galacto- and mannan-oligopolysaccharides and the related polymers, although pectic polysaccharides, which are rich in galacturonic acid and present in most of the plant primary cell walls [26], have so far received less attention [25]. As prebiotics are selectively fermented in the gut of a host, their metabolites can be utilized by other microorganisms, thus shifting the composition and activity of the gastrointestinal microbiota and hence benefiting the health of a host [27].

As knowledge concerning the effectiveness of pectic prebiotic supplementation in affecting bacterial taxonomic profiles in the chicken gut is scarce, the objective of this study was to examine the composition and structure of chicken gut bacteriobiome by estimating the diversity of phylogenetically significant fragments of $16 \mathrm{~S}$ rRNA genes from the excreta of chickens receiving antibiotic- or pectin-containing drinking water using high-throughput metagenomic sequencing.

\section{Materials and Methods}

\subsection{Chicken Breed and Experimental Design}

All experimental procedures involving chickens met the guidelines approved by the institutional animal care and use committee and were performed in accordance with the Russian National Law concerning the care of animals for research purposes, as well as being in compliance with the European Commission Directive 2010/63/EU on the protection of animals used for scientific purposes [28]. Chickens of the Ross 308 broiler breed were raised and grown at a poultry farm in the Omsk region, Russia.

From the first day of life to four weeks of age, the chicken were fed ad libitum with a starter diet and then from day 29 until the end of the experiment at 42 days of age they received the same feed without sunflower millcake (Table 1).

Table 1. Composition of the chicken broiler feed.

\begin{tabular}{ccc}
\hline Ingredients, $\mathbf{g} / \mathbf{k g}$ & Day $\mathbf{1 - 2 8}$ & Day 29-42 \\
\hline Wheat & 0.392 & 0.537 \\
Soya beans & 0.240 & 0.254 \\
Soyabean meal & 0.150 & 0.112 \\
Sunflower oil & 0.075 & 0.060 \\
Sunflower seed millcake & 0.100 & 0 \\
Methionine & 0.003 & 0.003 \\
Lysine & 0.003 & 0.003 \\
Sodium chloride & 0.003 & 0.003 \\
Calcium monophosphate & 0.012 & 0.012 \\
Limestone powder & 0.012 & 0.007 \\
Premix 1 & 0.010 & 0.010 \\
Crude protein, \% & 23 & 21 \\
Metabolic energy, MJ/kg & 13.0 & 13.2 \\
\hline
\end{tabular}

${ }^{1}$ A mixture of vitamins and micronutrients as per kilogram of feed: 500,000 IU vitamin A, 500,000 IU vitamin D3, $7.5 \mathrm{~g}$ vitamin E, $0.4 \mathrm{~g}$ vitamin $\mathrm{K} 3,0.3 \mathrm{~g}$ thiamine, $0.8 \mathrm{~g}$ riboflavin, $1.8 \mathrm{~g}$ d-pantothenic acid, $6.0 \mathrm{~g}$ nicotinic acid, $0.2 \mathrm{~g}$ folic acid, $20 \mathrm{mg}$ biotin, $2.5 \mathrm{mg}$ vitamin B12, $10 \mathrm{~g}$ Mn as manganese sulfate, $10 \mathrm{~g}$ Fe as ferrous sulfate, $8 \mathrm{~g} \mathrm{Zn}$ as zinc sulfate, $0.8 \mathrm{~g} \mathrm{Cu}$ as copper sulfate, $0.1 \mathrm{~g}$ Co as cobalt sulfate, $0.1 \mathrm{~g} \mathrm{I}$ as calcium iodide, and $15 \mathrm{mg}$ Se as sodium selenite.

The feed was manually distributed in the hopper feeders, suspended (to prevent the sawdust from getting into them) at the height of chicken backs; the height was adjusted during the birds' growth (at least once weekly). 
After 1 day of age, on the basis of body mass equality, the chicken were assembled in two groups of one hundred birds each, and both groups received conventional feed as described above. The chickens were grown on the deep litter of sawdust (coniferous) in a chamber separated by the net into two parts for the groups. The temperature in the chamber was maintained at $30^{\circ} \mathrm{C}-32^{\circ} \mathrm{C}$ up to 14 days of age, followed by $29^{\circ} \mathrm{C}-25^{\circ} \mathrm{C}$ from day 15 to 28 , and then by $+22^{\circ} \mathrm{C}-18{ }^{\circ} \mathrm{C}$ from day 29 onwards, with the relative humidity ranging $65-70 \%$ throughout the experiment.

The chicken received water from the tap (100 TDS) via nipple drinker systems with separate containers for each group. For the prophylaxis of the associative intestinal infections one group received pollodoxin antibiotic (Livisto, Barcelona, Spain) as $0.5 \mathrm{~mL}$ of the commercial preparation per one liter of drinking water at the age of 1-3, 14-16, 26-28 days, whereas the other group received $1 \%$ solution of the commercial prebiotic preparation Pepidol (Elusan Research and manufacturing Centre, Omsk, Russia), as $2 \mathrm{~mL} / \mathrm{bird}$ at the age of 1-3 days and $4 \mathrm{~mL} / \mathrm{bird}$ at the age of 14-16 and 26-28 days [29]. After being used for the prebiotic, the drinking system was rinsed and filled with tap water.

During the experiment the chicken survival was monitored. The living body mass at the age of 1,14, 28 and 42 days was measured individually, using the scales VK-600 and VK-3000 (Massa-K, Saint-Petersburg, Russia) for the birds up to and after 14 days of age, respectively. The feed intake was recorded daily as the difference between the daily feed supply and residual for each group.

\subsection{Sample Collection}

At 42 days of age, all birds were weighed, and eight apparently healthy chickens (four males and four females) were selected at random from each group. The birds were placed on a table and manually immobilized by one person firmly holding the wings and legs, while the other person collected the content of their cloaca by means of sterile grooved surgical probes in sterile plastic vials and frozen at $-196{ }^{\circ} \mathrm{C}$. In the laboratory the samples were stored at $-80^{\circ} \mathrm{C}$ prior to DNA extraction.

\subsection{Extraction of Total Nucleic Acid from Feces}

Total DNA was extracted from $250 \mathrm{mg}$ of feces using the DNeasy Powersoil Kit (Qiagen, Hilden, Germany) as per the manufacturer's instructions [30] to lyse microbial cells and obtain high-quality DNA solutions free from PCR inhibitors. The bead-beating was performed using TissueLyser II (Qiagen, Hilden, Germany) for $10 \mathrm{~min}$ at $30 \mathrm{~Hz}$. No further purification of the DNA was needed. The quality of the DNA was assessed using agarose gel electrophoresis.

\section{4. $16 S$ rRNA Gene Amplification and Sequencing}

The 16S DNA region was amplified with the primer pair F343 (5'-TACGGRAGGCAGC AG-3') and R803 (5'-CTACCAGGGTATCTAATCC-3') combined with Illumina adapter sequences [31]. PCR amplification was performed as described earlier [32]. A total of $200 \mathrm{ng}$ PCR product from each sample was pooled together and purified using a MinElute Gel Extraction Kit (Qiagen, Düsseldorf, Germany). The obtained libraries were sequenced with $2 \times 300$ bp paired-ends reagents on MiSeq (Illumina, San Diego, CA, USA) in the SB RAS Genomics Core Facility (ICBFM SB RAS, Novosibirsk, Russia). The read data reported in this study were submitted to GenBank under the study accession PRJNA number PRJNA523560.

\subsection{Bioinformatic and Statistical Analyses}

Raw sequences were analyzed with the UPARSE pipeline [33] using Usearch v11.0. The UPARSE pipeline included the merging of paired reads, read quality filtering, length trimming, merging of identical reads (dereplication), discarding singleton reads, removing chimeras and operational taxonomic unit (OTU) clustering using the UPARSE-OTU algo- 
rithm. The OTU sequences were assigned a taxonomy using the SINTAX [34] and 16S RDP training set v.16 [35].

The taxonomic structure of the obtained sequence assemblages was estimated based on the ratio of the number of taxon-specific sequence reads to the total number of sequence reads, i.e., based on the relative abundance of taxa, expressed as a percentage.

Descriptive statistics and ANOVA were performed using the Statistica v.13.3 software package (TIBCO Software Inc., Palo Alto, CA, USA). Comparison of the relative abundances of different bacterial taxa in cloaca samples between the groups was carried out using the post-hoc Fisher's LSD test. Factor effects and mean differences were considered statistically significant at the $p \leq 0.05$ level. The rarefaction curves were obtained using iNEXT 2.0.15 in the R package [36], and OTU-based $\alpha$-diversity indices were calculated using Usearch v11.0 [33].

\section{Results}

\subsection{Taxonomic Richness and Structure of Chicken Cloaca Bacteriobiome}

After $16 \mathrm{~S}$ gene amplicon sequencing, quality filtering and chimera removal, a total of 412,960 high-quality DNA sequences were obtained from the excreta of the 16 chickens. High-quality reads were clustered using $>97 \%$ sequence identity into 397 bacterial operational taxonomic units (OTUs). The obtained sets of sequences for each sample were analyzed by plotting the number of OTUs against the total number of sequence reads, and the resulting rarefaction curves demonstrated sufficient OTU coverage to describe the bacteriobiome composition in different groups [37].

The total number of different taxon levels identified in the study is shown in Table 2. The most OTU-rich phyla were Firmicutes (346 OTUs, or $87 \%$ of the total number of identified OTUs), followed by Proteobacteria (12 OTUs, or 3\%) and Bacteroidetes (seven OTUs, or $2 \%$ ). Taxonomic richness in the studied samples was found to decrease drastically if only the dominant members, i.e., the ones contributing at least $1 \%$ into the total number of sequence reads, of the bacterial assemblages, were taken into account (Table 2).

Table 2. Taxonomic richness of cloaca bacterial assemblages of the chickens.

\begin{tabular}{ccccc}
\hline \multirow{2}{*}{ Taxon Level } & \multicolumn{3}{c}{ Taxonomic Attribution } \\
\cline { 2 - 5 } & \multirow{2}{*}{ All OTUs } & \multicolumn{3}{c}{ Dominant OTUs } \\
\cline { 3 - 5 } & & Both Groups & Antibiotic-Receiving & Prebiotic-Receiving \\
\hline Phylum & 9 & 3 & 3 & 2 \\
Class & 17 & 6 & 4 & 3 \\
Order & 26 & 8 & 8 & 3 \\
Family & 41 & 12 & 10 & 5 \\
Genus & 96 & 18 & 12 & 7 \\
OTU & 397 & & & 7 \\
\hline
\end{tabular}

Three bacterial phyla-Firmicutes, Bacteroidetes and Proteobacteria-collectively accounted for more than $95 \%$ of the total sequence reads of the cloaca bacteriobiome (Figure 1a). The overwhelming majority of sequences represented four classes (Figure 1b) and four orders (Figure 1c), with four families being major dominants, i.e., their relative abundance being around 10\% (Figure 1d). 


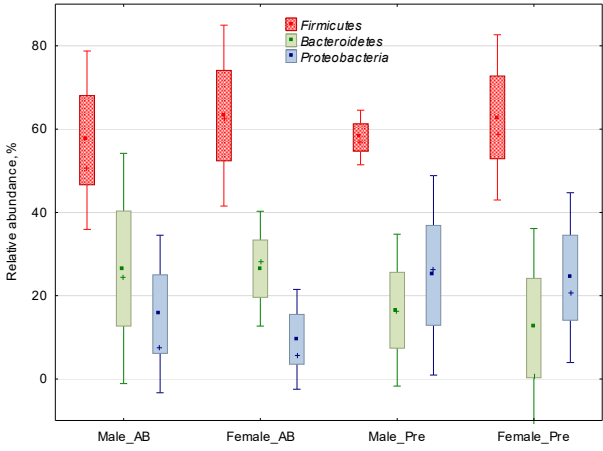

(a)

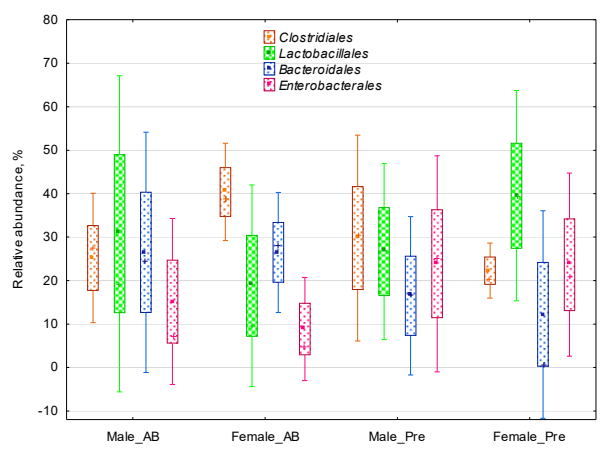

(c)

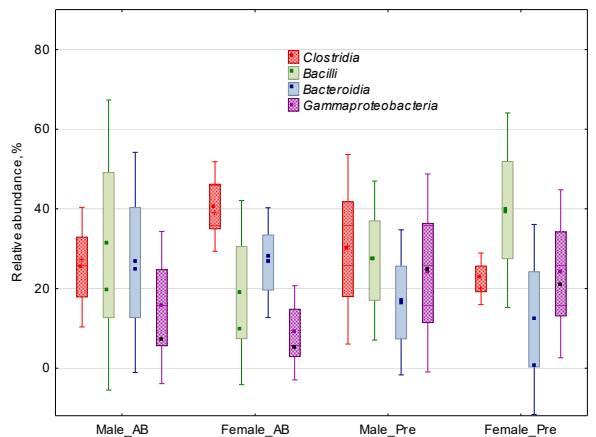

(b)

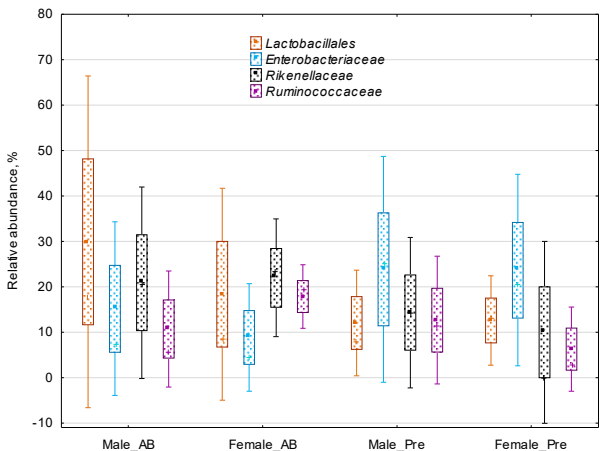

(d)

Figure 1. Relative abundance of taxon-specific sequences in the cloaca bacteriobiome of the antibioticand prebiotic-receiving chickens: (a) phylum; (b) class; (c) order and (d) family levels. The markers show mean (solid square) and median (plus), boxes show standard error, and the lines indicate standard deviation. Codes: Male_AB, Female_AB_-male and female chickens in the antibioticrececiving group); Male_Pre, Female_Pre-male and female chickens in the prebiotic group.

\subsection{OTU Relative Abundance in the Chicken Cloaca Bacteriobiome}

Of the total number of OTUs detected in the studied samples, only 18 OTUs, or $4.5 \%$, were dominants, i.e., contributing $\geq 1 \%$ to the total number of sequences (Table 3 ). The number of dominant OTUs ranged from 7-12 in a group, with just two OTUs being common for all four groups (Escherichia/Shigella sp. and Lactobacillus sp.).

As the groups differing in prebiotic supplementation and sex contained four birds each (hence complying with any data distribution pattern), we performed factorial ANOVA on the relative abundance of the OTUs (Table 4). For most OTUs displaying statistically significant effects of any of the studied factors, prebiotic supplementation accounted for the substantial part of the relative abundance data variance: roughly ranging from one fifth to one half, being maximal (56\%) in the case of Streptococcus sp. and negligible in the case of Anaeromassilibacillus sp. and Blautia hydrogenotrophica, as well as some unclassified Lachnospiraceae, Ruminococcaceae and Clostridiales. Notably, the former four OTUs' data variance was mostly (37\%) determined by the interaction between prebiotic and sex (Table 4).

Overall, 42 OTUs were found to have differential relative abundance in the cloaca microbiota of the studied groups (Table 5). Most of these OTUs (34) were minor or rare bacteriobiome members, accounting for much less than $1 \%$ of the total number of sequence reads.

In the antibiotic-receiving group, 17 OTUs had higher relative abundance in the female cloaca bacteriobiome as compared to the male one, and two OTUs had higher abundances in the males (Table 5). In the prebiotic-receiving group, only four OTUs had sex-related difference in relative abundance, with females having lower values. 
For some bacteria, the effect of prebiotic supplementation was strongly sex-related. For instance, in the male bacteriobiome Ligilactobacillus sp. and L. agilis decreased, whereas Ruminococcus bromii and some unclassified Clostridiales increased (Table 5) in their relative abundance. In the female bacteriobiome the prebiotic supplementation decreased the levels of Clostridium spiroforme, Butyricicoccus pullicaecorum, Negativibacillus massiliensis, Eubacterium sp., as well as some unclassified Clostridiales, Lachnospiraceae, Ruminococcaceae, Clostridium XVIII, Erysipelotrichaceae and Firmicutes. The effect of prebiotic supplementation on some other bacteria was similarly displayed by both sexes: for instance, Enterococcus sp., Streptococcus sp. and Bifidobacterium sp. increased, whereas Bifidobacterium pullorum decreased.

In both male and female chickens, supplementation with prebiotics instead of antibiotics resulted in the apparently drastically increased relative abundance of Escherichia/Shigella sp., although the effect was not statistically significant $(p=0.55$ for the males and $p=0.31$ for the females).

Table 3. Relative abundance (\%) of OTUs, dominant in the cloaca bacteriobiome of male and female chickens of the control and prebiotic-receiving groups: median (25-75\% interquartile range).

\begin{tabular}{|c|c|c|c|}
\hline & OTU & Antibiotic Group & Prebiotic Group \\
\hline \multicolumn{4}{|c|}{ Males } \\
\hline 1 & Escherichia/Shigella sp. & $7.1(20.6)$ & $24.5(42.5)$ \\
\hline 2 & Alistipes sp. & $20.4(35.8)$ & $14.0(28.1)$ \\
\hline 3 & Enterococcus sp. & $0.0(0.0)$ & $4.9(22.4)$ \\
\hline 4 & Lactobacillus sp. & $6.3(28.4)$ & $3.6(9.7)$ \\
\hline 5 & Romboutsia timonensis & $1.9(5.8)$ & $4.8(3.0)$ \\
\hline 6 & Lactobacillus sp. & $2.1(4.6)$ & $2.5(5.4)$ \\
\hline 7 & Faecalibacterium prausnitzii & $1.3(4.0)$ & $2.4(5.6)$ \\
\hline 8 & un. ${ }^{1}$ Clostridiaceae & $0.1(3.2)$ & $1.5(3.9)$ \\
\hline 9 & Ligilactobacillus sp. & $4.9(5.9)$ & $0.6(0.5)$ \\
\hline 10 & un. Lachnospiraceae & $0.9(3.3)$ & $2.0(4.1)$ \\
\hline 12 & un. Muribaculaceae & $3.6(9.3)$ & $0.8(2.3)$ \\
\hline 13 & Streptococcus sp. & $0.0(0.0)$ & $1.9(3.5)$ \\
\hline 15 & un. Ruminococcaceae & $0.3(1.1)$ & $1.0(1.8)$ \\
\hline 17 & Limosilactobacillus sp. & $1.6(17.1)$ & $0.8(1.7)$ \\
\hline \multirow[t]{2}{*}{26} & un. Lachnospiraceae & $1.1(2.0)$ & $1.2(2.1)$ \\
\hline & \multicolumn{3}{|c|}{ Females } \\
\hline 1 & Escherichia/Shigella sp. & $4.6(15.6)$ & $20.4(32.2)$ \\
\hline 2 & Alistipes sp. & $23.2(21.3)$ & $0.0(19.4)$ \\
\hline 3 & Enterococcus sp. & $0.00(0.0)$ & $23.6(39.7)$ \\
\hline 4 & Lactobacillus sp. & $3.2(19.2)$ & $2.4(6.4)$ \\
\hline 5 & Romboutsia timonensis & $0.8(3.3)$ & $6.6(14.9)$ \\
\hline 7 & Faecalibacterium prausnitzii & $5.1(7.3)$ & $0.0(2.1)$ \\
\hline 8 & un. Clostridiaceae & $0.2(0.6)$ & $2.8(5.8)$ \\
\hline 10 & un. Lachnospiraceae & $5.7(3.9)$ & $0.0(1.4)$ \\
\hline 12 & un. Muribaculaceae & $2.5(4.2)$ & $0.4(3.1)$ \\
\hline 13 & Streptococcus sp. & $0.0(0.1)$ & $4.0(2.2)$ \\
\hline 14 & un. Bacteroides & $1.6(1.3)$ & $0.0(1.0)$ \\
\hline 16 & un. Clostridiales & $2.7(3.2)$ & $0.0(0.05)$ \\
\hline 17 & Limosilactobacillus sp. & $1.7(5.1)$ & $1.7(0.9)$ \\
\hline 20 & Blautia sp. & $1.0(0.6)$ & $0.4(1.4)$ \\
\hline 23 & un. Ruminococcaceae & $1.0(1.0)$ & $0.00(0.1)$ \\
\hline 26 & un. Lachnospiraceae & $3.6(2.1)$ & $0.3(0.6)$ \\
\hline
\end{tabular}

${ }^{1}$ un. stands for unclassified. 
Table 4. ANOVA results for OTUs in the cloaca bacteriobiome of male and female chickens: factor contribution $(\%)$ in the total data variance.

\begin{tabular}{|c|c|c|c|c|}
\hline & \multirow{2}{*}{ OTU } & \multicolumn{3}{|c|}{ Factor } \\
\hline & & Prebiotic & Sex & Prebiotic $\times$ Sex \\
\hline 3 & Enterococcus sp. & $30.7^{1}$ & 3.4 & 3.4 \\
\hline 9 & Ligilactobacillus sp. & 25.6 & 8.2 & 6.6 \\
\hline 13 & Streptococcus sp. & 56.2 & 0.5 & 0.3 \\
\hline 16 & un. ${ }^{2}$ Clostridiales & 28.0 & 5.9 & $\underline{14.0}$ \\
\hline 22 & Clostridium spiroforme & $14.1^{3}$ & $\underline{14.1}$ & $\overline{21.3}$ \\
\hline 23 & un. Ruminococcaceae & 28.0 & 3.0 & 6.1 \\
\hline 24 & Bifidobacterium pullorum & 39.8 & 1.0 & 1.8 \\
\hline 26 & un. Lachnospiraceae & 24.1 & 3.9 & 27.2 \\
\hline 29 & un. Clostridiales & 0.1 & 1.7 & 37.8 \\
\hline 34 & un. Lachnospiraceae & 6.6 & 0.4 & 29.9 \\
\hline 46 & Butyricicoccus pullicaecorum & 31.2 & 3.0 & 8.1 \\
\hline 51 & un. Ruminococcaceae & 25.4 & 5.6 & 19.5 \\
\hline 52 & un. Firmicutes & 30.6 & 13.0 & 7.0 \\
\hline 54 & un. Clostridium XVIII & 45.5 & $\overline{8.3}$ & 18.8 \\
\hline 59 & un. Clostridiales & 29.6 & $\overline{6.3}$ & 10.4 \\
\hline 71 & Negativibacillus massiliensis & 18.1 & 0.9 & 24.1 \\
\hline 78 & un. Clostridiales & 26.6 & 3.3 & 9.0 \\
\hline 87 & Bifidobacterium sp. & 48.4 & 1.0 & 1.0 \\
\hline 93 & Anaeromassilibacillus sp. & 0.7 & 2.5 & 27.7 \\
\hline 98 & un. Firmicutes & 28.9 & 10.9 & 24.0 \\
\hline 114 & Massilimicrobiota timonensis & 33.9 & $\overline{18.3}$ & 28.2 \\
\hline 126 & Monoglobus sp. & 22.3 & 9.1 & 19.1 \\
\hline 136 & un. Lachnospiraceae & 4.5 & 1.4 & 29.6 \\
\hline 140 & Blautia hydrogenotrophica & 0.4 & 0.9 & 37.6 \\
\hline 143 & un. Lachnospiraceae & 20.3 & 3.1 & 27.3 \\
\hline 152 & Clostridium colinum & 27.6 & 2.2 & 1.6 \\
\hline 157 & un. Lachnospiraceae & 0.2 & 1.2 & 35.7 \\
\hline 158 & un. Ruminococcaceae & 1.3 & $\underline{12.7}$ & 38.0 \\
\hline 169 & un. Clostridiales & 27.9 & 3.3 & 14.0 \\
\hline 183 & Ligilactobacillus agilis & 42.6 & 5.0 & $\overline{4.0}$ \\
\hline 194 & un. Ruminococcaceae & 15.2 & 18.3 & 25.1 \\
\hline 203 & un. Firmicutes & 28.1 & 2.8 & 24.6 \\
\hline 224 & un. Lachnospiraceae & 19.5 & 9.8 & 21.6 \\
\hline 228 & Staphylococcus sp. & 30.5 & 1.9 & 1.9 \\
\hline 231 & un. Clostridium IV & 29.6 & 0.0 & 0.0 \\
\hline 246 & un. Lachnospiraceae & 23.2 & 0.6 & $\underline{18.4}$ \\
\hline 251 & un. Clostridiales & 32.6 & 0.0 & $\overline{0.8}$ \\
\hline 257 & un. Lachnospiraceae & 27.0 & 3.7 & 9.5 \\
\hline 339 & Butyricicoccus sp. & 37.6 & 0.1 & 0.5 \\
\hline 347 & Paludicola sp. & 30.9 & 0.6 & 0.6 \\
\hline 357 & un. Firmicutes & 25.6 & 13.7 & 24.5 \\
\hline 374 & un. Ruminococcaceae & 22.7 & 22.7 & 22.7 \\
\hline
\end{tabular}

${ }^{1}$ Factor contribution values in bold denote that the effect was significant ( $p \leq 0.05$, ANOVA). ${ }^{2}$ un. stands for unclassified; ${ }^{3}$ the underscored values denote that the $p$-value of the effect was $0.05 \leq p \leq 0.10$, ANOVA). 
Table 5. Differential abundance (\%) of OTUs in the cloaca bacteriobiome of the male and female chickens in the antibiotic- and prebiotic-receiving groups (mean values).

\begin{tabular}{|c|c|c|c|c|c|}
\hline & \multirow{2}{*}{ OTU } & \multicolumn{2}{|c|}{ Antibiotic Group } & \multicolumn{2}{|c|}{ Prebiotic Group } \\
\hline & & Male & Female & Male & Female \\
\hline 3 & Enterococcus sp. & $0.0 \mathrm{a}^{1}$ & $0.0 \mathrm{a}$ & $11.6 \mathrm{~b}$ & $23.2 \mathrm{~b}$ \\
\hline 9 & Ligilactobacillus sp. & $4.3 \mathrm{~b}$ & $1.7 \mathrm{ab}$ & $0.6 \mathrm{a}$ & $0.5 \mathrm{a}$ \\
\hline 13 & Streptococcus sp. & $0.0 \mathrm{a}$ & $0.1 \mathrm{a}$ & $3.0 \mathrm{~b}$ & $3.5 \mathrm{~b}$ \\
\hline 16 & un. ${ }^{2}$ Clostridiales & $0.9 \mathrm{ab}$ & $2.6 \mathrm{~b}$ & $0.4 \mathrm{a}$ & $0.0 \mathrm{a}$ \\
\hline 22 & Clostridium spiroforme & $0.2 \mathrm{a}$ & $0.9 \mathrm{~b}$ & $0.2 \mathrm{a}$ & $0.2 \mathrm{a}$ \\
\hline 23 & un. Ruminococcaceae & $0.9 \mathrm{~b}$ & $1.0 \mathrm{~b}$ & $0.6 \mathrm{ab}$ & $0.1 \mathrm{a}$ \\
\hline 24 & Bifidobacterium pullorum & $0.4 \mathrm{ab}$ & $0.5 \mathrm{~b}$ & $0.1 \mathrm{a}$ & $0.1 \mathrm{a}$ \\
\hline 26 & un. Lachnospiraceae & $1.2 \mathrm{a}$ & $3.2 \mathrm{~b}$ & $1.3 \mathrm{a}$ & $0.3 \mathrm{a}$ \\
\hline 29 & un. ${ }^{2}$ Clostridiales & $0.1 \mathrm{a}$ & $0.4 \mathrm{ab}$ & $0.4 \mathrm{~b}$ & $0.0 \mathrm{a}$ \\
\hline 34 & un. Lachnospiraceae & $0.2 \mathrm{~b}$ & $0.6 \mathrm{~b}$ & $0.4 \mathrm{~b}$ & $0.1 \mathrm{a}$ \\
\hline 46 & Butyricicoccus pullicaecorum & $0.5 \mathrm{ab}$ & $1.1 \mathrm{~b}$ & $0.2 \mathrm{a}$ & $0.0 \mathrm{a}$ \\
\hline 51 & un. Ruminococcaceae & $0.1 \mathrm{a}$ & $0.2 \mathrm{~b}$ & $0.1 \mathrm{a}$ & $0.0 \mathrm{a}$ \\
\hline 52 & un. Firmicutes & $0.2 \mathrm{a}$ & $0.5 \mathrm{~b}$ & $0.0 \mathrm{a}$ & $0.1 \mathrm{a}$ \\
\hline 54 & un. Clostridium XVIII & $0.11 \mathrm{a}$ & $0.26 \mathrm{~b}$ & $0.05 \mathrm{a}$ & $0.02 \mathrm{a}$ \\
\hline 59 & un. Clostridiales & $0.08 \mathrm{ab}$ & $0.22 \mathrm{~b}$ & $0.03 \mathrm{a}$ & $0.01 \mathrm{a}$ \\
\hline 71 & Negativibacillus massiliensis & $0.17 \mathrm{a}$ & $0.44 \mathrm{~b}$ & $0.20 \mathrm{ab}$ & $0.06 \mathrm{a}$ \\
\hline 78 & un. Clostridiales & $0.41 \mathrm{ab}$ & $0.85 \mathrm{~b}$ & $0.21 \mathrm{a}$ & $0.11 \mathrm{a}$ \\
\hline 87 & Bifidobacterium sp. & $0.00 \mathrm{a}$ & $0.00 \mathrm{a}$ & $0.13 \mathrm{~b}$ & $0.17 \mathrm{~b}$ \\
\hline 93 & Anaeromassilibacillus sp. & $0.2 \mathrm{a}$ & $0.9 \mathrm{a}$ & $0.1 \mathrm{a}$ & $0.1 \mathrm{a}$ \\
\hline 98 & un. Firmicutes & $0.03 \mathrm{a}$ & $0.11 \mathrm{~b}$ & $0.03 \mathrm{a}$ & $0.01 \mathrm{a}$ \\
\hline 114 & Massilimicrobiota timonensis & $0.02 \mathrm{a}$ & $0.10 \mathrm{~b}$ & $0.02 \mathrm{a}$ & $0.01 \mathrm{a}$ \\
\hline 126 & Monoglobus sp. & $0.02 \mathrm{a}$ & $0.07 \mathrm{~b}$ & $0.02 \mathrm{a}$ & $0.01 \mathrm{a}$ \\
\hline 140 & Blautia hydrogenotrophica & $0.01 \mathrm{a}$ & $0.04 \mathrm{ab}$ & $0.05 \mathrm{~b}$ & $0.01 \mathrm{a}$ \\
\hline 143 & un. Lachnospiraceae & $0.03 \mathrm{a}$ & $0.11 \mathrm{~b}$ & $0.04 \mathrm{a}$ & $0.00 \mathrm{a}$ \\
\hline 152 & Clostridium colinum & $0.05 \mathrm{~b}$ & $0.03 \mathrm{a}$ & $0.00 \mathrm{a}$ & $0.00 \mathrm{a}$ \\
\hline 157 & un. Lachnospiraceae & $0.01 \mathrm{a}$ & $0.03 \mathrm{~b}$ & $0.03 \mathrm{~b}$ & $0.00 \mathrm{a}$ \\
\hline 158 & un. Ruminococcaceae & $0.01 \mathrm{a}$ & $0.07 \mathrm{~b}$ & $0.04 \mathrm{a}$ & $0.02 \mathrm{a}$ \\
\hline 169 & un. Clostridiales & $0.03 \mathrm{ab}$ & $0.07 \mathrm{~b}$ & $0.01 \mathrm{a}$ & $0.00 \mathrm{a}$ \\
\hline 183 & Ligilactobacillus agilis & $0.04 \mathrm{~b}$ & $0.02 \mathrm{a}$ & $0.00 \mathrm{a}$ & $0.00 \mathrm{a}$ \\
\hline 194 & un. Ruminococcaceae & $0.00 \mathrm{a}$ & $0.03 \mathrm{~b}$ & $0.01 \mathrm{a}$ & $0.00 \mathrm{a}$ \\
\hline 203 & un. Firmicutes & $0.01 \mathrm{a}$ & $0.03 \mathrm{~b}$ & $0.01 \mathrm{a}$ & $0.00 \mathrm{a}$ \\
\hline 224 & un. Lachnospiraceae & $0.03 \mathrm{a}$ & $0.08 \mathrm{~b}$ & $0.03 \mathrm{a}$ & $0.02 \mathrm{a}$ \\
\hline 228 & Staphylococcus sp. & $0.00 \mathrm{a}$ & $0.00 \mathrm{a}$ & $0.02 \mathrm{~b}$ & $0.03 \mathrm{~b}$ \\
\hline 231 & un. ClostridiumIV & $0.01 \mathrm{~b}$ & $0.01 \mathrm{~b}$ & $0.00 \mathrm{a}$ & $0.00 \mathrm{a}$ \\
\hline 246 & un. Lachnospiraceae & $0.045 \mathrm{ab}$ & $0.096 \mathrm{~b}$ & $0.040 \mathrm{ab}$ & $0.004 \mathrm{a}$ \\
\hline 251 & un. Clostridiales & $0.01 \mathrm{a}$ & $0.01 \mathrm{a}$ & $0.00 \mathrm{a}$ & $0.00 \mathrm{a}$ \\
\hline 257 & un. Lachnospiraceae & $0.005 \mathrm{ab}$ & $0.013 \mathrm{~b}$ & $0.002 \mathrm{a}$ & $0.000 \mathrm{a}$ \\
\hline 339 & Butyricicoccus sp. & $0.03 \mathrm{a}$ & $0.03 \mathrm{a}$ & $0.00 \mathrm{a}$ & $0.00 \mathrm{a}$ \\
\hline 347 & Paludicola sp. & $0.005 \mathrm{a}$ & $0.004 \mathrm{a}$ & $0.000 \mathrm{a}$ & $0.000 \mathrm{a}$ \\
\hline 357 & un. Firmicutes & $0.00 \mathrm{a}$ & $0.01 \mathrm{~b}$ & $0.00 \mathrm{a}$ & $0.00 \mathrm{a}$ \\
\hline 374 & un. Ruminococcaceae & $0.000 \mathrm{a}$ & $0.003 \mathrm{~b}$ & $0.000 \mathrm{a}$ & $0.000 \mathrm{a}$ \\
\hline
\end{tabular}

${ }^{1}$ Different letters in rows denote that the values differ ( $p \leq 0.05$, Fisher's LSD test). ${ }^{2}$ un. stands for unclassified.

\subsection{Biodiversity Indices of the Chicken Cloaca Bacteriobiome}

For each cloaca bacterial assemblage, i.e., a matrix with the number of sequence reads for each OTU, we calculated several $\alpha$-biodiversity indices (Tables 6 and 7). The prebiotic supplementation had a marked contribution in terms of the species richness, i.e., the total number of OTUs, both observed and potential, as estimated by Chao-1 (Table 6), mostly due to decreasing the observed richness by 2.4 times $(p=0.093)$ and the potential richness by 2.2 times $(p=0.049)$ in the hens' bacteriobiome (Table 7$)$. 
Table 6. ANOVA results for $\alpha$-biodiversity indices in the cloaca bacteriobiome of male and female chickens: factor contribution (\%) in the total data variance.

\begin{tabular}{cccc}
\hline \multirow{2}{*}{ Index } & \multicolumn{3}{c}{ Factor } \\
\cline { 2 - 4 } & Prebiotic & Sex & Prebiotic $\times$ Sex \\
\hline Total number of identified OTUs & 19.3 & 0.0 & 10.6 \\
Chao-1 & 26.3 & 0.0 & 7.8 \\
Simpson (1-D) & 9.1 & 1.0 & 17.4 \\
Shannon & 9.0 & 0.5 & 13.7 \\
Equitability & 1.9 & 1.7 & 16.7 \\
Dominance (D) & 9.2 & 1.0 & 17.3 \\
Berger-Parker & 4.8 & 3.0 & 32.6 \\
\hline
\end{tabular}

Table 7. Alpha-biodiversity indices for OTUs in the cloaca bacteriobiome of male and female chickens of the control and prebiotic-receiving group (mean values).

\begin{tabular}{ccccc}
\hline \multirow{2}{*}{ Index } & \multicolumn{2}{c}{ Antibiotic Group } & \multicolumn{2}{c}{ Prebiotic Group } \\
\cline { 2 - 5 } & Male & Female & Male & Female \\
\hline Number of identified OTUs & $202 \mathrm{ab}$ & $269 \mathrm{~b}$ & $178 \mathrm{ab}$ & $112 \mathrm{a}$ \\
Chao-1 & $249 \mathrm{ab}$ & $307 \mathrm{~b}$ & $199 \mathrm{ab}$ & $139 \mathrm{a}$ \\
Simpson (1-D) & 0.78 & 0.87 & 0.80 & 0.75 \\
Shannon & 2.5 & 3.2 & 2.6 & 2.1 \\
Equitability & 0.47 & 0.57 & 0.52 & 0.47 \\
Dominance (D) & 0.22 & 0.13 & 0.20 & 0.25 \\
Berger-Parker & $0.43 \mathrm{~b}$ & $0.29 \mathrm{a}$ & $0.37 \mathrm{ab}$ & $0.44 \mathrm{~b}$ \\
\hline
\end{tabular}

${ }^{1}$ Different letters in rows denote that the values differ ( $p \leq 0.05$, Fisher's LSD test).

Notably, there was a statistically significant difference in the Berger-Parker $\alpha$-biodiversity index-i.e., the maximum percentage of an OTU in the bacteriobiome- between the sexes in the antibiotic-receiving group, and between control and prebiotic-receiving hens (Table 7).

\subsection{Production Performance of Chickens}

The data on production characteristics for the entire groups, i.e., consisting of 100 birds each, were normally distributed: ANOVA showed that prebiotic supplementation accounted for $43 \%$ of the bird body mass variance at day 42 and for $30 \%$ of the growth rate variance. Thus, due to the beneficial effect of prebiotic-enriched drinking water, chickens ${ }^{\prime}$ production characteristics improved, as the prebiotic-receiving chickens demonstrated (Table 8 ) both a higher daily mass increase rate (by $4.0 \mathrm{~g} / \mathrm{bird}$ ) and total body mass at the end of the rearing period (by $235 \mathrm{~g} / \mathrm{bird}$ ). This finding is in agreement with an earlier report about the enhanced production performance of prebiotic-receiving chicken broilers [36].

Table 8. Production characteristics of male and female chickens of the antibiotic- and prebioticreceiving groups (mean values, $n=8,4$ males and 4 females).

\begin{tabular}{ccccc}
\hline \multirow{2}{*}{ Index } & \multicolumn{2}{c}{ Antibiotic Group } & \multicolumn{2}{c}{ Prebiotic Group } \\
\cline { 2 - 5 } & Male & Female & Male & Female \\
\hline $\begin{array}{c}\text { Living mass of a 42-day-old } \\
\text { chickens, g/bird }\end{array}$ & $2210.1 \mathrm{c}^{1}$ & $1832.7 \mathrm{a}$ & $2352.8 \mathrm{~d}$ & $1939.7 \mathrm{~b}$ \\
Average daily gain, g/bird per day & $51.6 \mathrm{c}$ & $42.6 \mathrm{a}$ & $55.0 \mathrm{~d}$ & $45.2 \mathrm{~b}$ \\
\hline
\end{tabular}

${ }^{1}$ Different letters in rows denote that the values differ ( $p \leq 0.05$, Fisher's LSD test).

Supplementing conventional chicken drink with prebiotics resulted in $0.11 \mathrm{~kg}$ less feed consumption per $1 \mathrm{~kg}$ of chicken living mass (Table 9); the difference translated into $19.7 \%$ profitability in the probiotic-receiving group as compared with $8.1 \%$ in the antibiotic-receiving one. 
Table 9. Production characteristics of chickens in the antibiotic- and prebiotic-receiving groups (mean values, $n=100)$.

\begin{tabular}{lcc}
\hline \multicolumn{1}{c}{ Characteristic } & Antibiotic Group & Prebiotic Group \\
\hline Living mass of 1-day-old chickens, g/bird & $43.3 \pm 0.3$ & $43.2 \pm 0.3$ \\
\hline Living mass of 42-day-old chickens, g/bird3 & $2021.4 \pm 21.4$ & $2144.3 \pm 30.5$ \\
\hline Average daily gain, g/bird per day & $47.1 \pm 2.1$ & $50.03 \pm 2.3$ \\
\hline Feed intake, $\mathrm{kg} / \mathrm{kg}$ bird mass & 2.04 & 1.93 \\
\hline Survival over 42 days, $\%$ & 94 & 99 \\
\hline
\end{tabular}

\section{Discussion}

\subsection{Taxonomic Richness and Structure of the Chicken Cloaca Bacteriobiome}

The finding that the Firmicutes phylum ultimately prevailed in the chicken' cloaca bacteriobiome agrees with the results obtained in other studies: for instance, the representatives of Firmicutes accounted for more than $60 \%$ of the chicken gut bacteriobiome [38,39]. Similarly to other reported results [38-41], we also found that three bacterial phyla, namely Firmicutes, Bacteroidetes and Proteobacteria, together comprised more than $90 \%$ of the total number of sequence reads. At the family level the structure of the chicken bacteriobiome in our study was very close to the one reported for broiler chickens from several Eastern-European farms [41], with the Lactobacillaceae family prevailing.

The 3.5-4.0-fold increase in the relative abundance of the Escherichia / Shigella bacterium (up to $1 / 5$ th- $1 / 4$ th of the bacteriobiome) in both the male and female prebiotic-receiving groups was not statistically significant. However, this was expected, as antibiotic supplementation in the respective group kept the pathogen in check in contrast to the prebioticreceiving group, where the absence of antibiotic treatment benefited the bacterium. The apparently rather high variation in its relative abundance might have been due to the inter-individual variation in the bacteriobiome's change rate and rather short period of life/treatment. The genus Escherichia/Shigella contains important pathogens of humans and animals [42], but can also be represented by non-pathogenic strains; therefore, the apparent shift can hardly be interpreted unequivocally in respect to birds' health and welfare. However, earlier reports described highly dominant OTUs of this genus in apparently healthy birds [43]. Thus, our finding of the high dominance of one Escherichia/Shigella OTU in healthy broilers suggests the regular commensal character of the strain.

Two other OTUs with marked and statistically significant increases in their relative abundance were Enterococcus sp. and Streptococcus sp. The Enterococcus genus is a known component of the normal chicken gut microbiota [44], with some of its representatives (E. faecium) displaying a beneficial probiotic effect by controlling pathogens $[45,46]$. However, enterococci are often implicated in opportunistic infections [47], and recently it was stated that infections caused by E. cecorum form "an important emerging disease in modern broiler chickens associated with arthritis and osteomyelitis and leading to high mortality rates" [48]. Interestingly, the pathogenic strains were identified in the intestines of naturally infected birds much earlier in life as compared to commensal E. cecorum strains [49]. As for the Streptococcus genus, similarly to Enterococcus, it contains commensal [50] as well as pathogenic strains of humans and animals, including poultry (for example, causing meningitis in ducks [51]). However, within the context of better growth and production performance of the prebiotic-receiving chickens in our study, both Enterococcus sp. and Streptococcus sp. OTUs were most likely commensal strains.

The fact that 30 of the 32 bacterial OTUs, displaying the effect of prebiotic treatment, belonged to the Firmicutes phylum, proves that Firmicutes, as a core phylum, contained representatives responding to dietary specifics. However, only five of these 30 prebioticdifferential Firmicutes OTUs were identified down to a species level (Tables 4 and 5), namely, Butyricicoccus pullicaecorum, Negativibacillus massiliensis, Massilimicrobiota timonensis, Clostridium colinum and Ligilactobacillus agilis. Nine OTUs were identified down to the genus 
level, whereas eight OTUs were classified to the family level. The rest of the differential Firmicutes OTUs were identified only at higher levels (phylum and order, four OTUs each). Butyricicoccus pullicaecorum is a well-known butyrate-producing member of the intestinal microbiome, and as such is beneficial for chickens' health [52]; however, our study showed its decreased relative abundance in the prebiotic-receiving females. This finding helps to obtain better insights into the microbiota-shifting positive effect of antibiotic supplementation in chickens' drinking water. A similar change was shown by Ligilactobacillus agilis and Ligilactobacillus sp. OTUs, as they decreased their presence in the prebiotic-receiving group; these bacteria are known as especially effective chicken gut commensal colonizers [53]. Another prebiotic-differential firmicute in females, Massilimicrobiota timonensis, was identified rather recently and currently there is no information that can be speculatively used for implying its role in intestinal microbiota functioning, especially at its abundance of less than $0.1 \%$. Clostridium colinum, found only in the cloaca bacteriobiome of the antibiotic-receiving broilers, is known to cause ulcerative enteritis [54], one of the major clostridial enteric disease of poultry; thus, its absence in the pectin-receiving group was beneficial for the birds. As most of the differential OTUs in our study were not identified down to the species and even genus level, we believe that performing whole-genome sequencing of the gut microbiome can provide data that would be more readily interpretable ecophysiologically.

Prebiotic-related changes in the other two OTUs, belonging to the Actinobacteria phylum, are difficult to interpret because Bifidobacterium pullorum, which is mainly a characteristic of birds [55], had a decreased abundance in the prebiotic-treated chickens as compared with the antibiotic-receiving ones, whereas another Bifidobacterium OTU had a markedly increased presence in the prebiotic-treated chickens.

Our study revealed, both statistically $(p \leq 0.05)$ and bacterially (about $20-25 \%$ of the relative abundance variance), the effect of the interaction between sex and the prebiotic supplementation on the chickens' bacteriobiome. This effect was displayed by the OTUs, representing Lachnospiraceae, Rumunococcaceae, unclassified Clostridiales, Clostridium spiroforme, Blautia hydrogenotrophica, Negativibacillus massiliensis, Monoglobus sp. and un. Clostridium XVIII. This result agrees with some earlier findings: for instance, an interaction between probiotic treatment and sex for Bifidobacterium was found in 42-day-old broilers [56]. As for an ecophysiological role, this can be suggested for the identified differential OTUs. Clostridium spiroforme is a known pathogen causing enteric infections [57], whereas Blautia hydrogenotrophica is beneficial for a host as the bacterium helps to break down and ferment plant materials [58]. Although little is known about the physiology of Negativibacillus massiliensis, as a representative of the Ruminococcaceae family the bacterium is most likely involved in the breakdown if cellulose [59]. Under antibiotic control, $N$. massiliensis had the same relative abundance in birds of both sexes, but in the pectinreceiving group there was an increase in the abundance of $N$. massiliensis in males and a decrease in females. Monoglobus sp., a rare member of the chicken cloaca bacteriobiome, was most likely involved in pectin degradation [60], showing increased abundance in the pectin-receiving females.

Within both groups there we some sex-related differences in the bacteriobiome structure. The finding that much more OTUs displayed sex-related differential relative abundance in the antibiotic-receiving group as compared to the prebiotic-receiving one (19 vs. 4 , Table 5) strongly suggests that different mechanisms were involved in shaping the chicken gut bacteriobiome under the two supplementations studied.

The finding that, with the exception of four OTUs (namely, Enterococcus sp., Ligilactobacillus sp., Streptococcus sp. and an unclassified Clostridiales), most of the differentially abundant OTUs in the cloaca bacteriobiomes of the antibiotic- and prebiotic-receiving groups were minor or rare members, indicating that low-abundance OTUs are important for the host's adjustments to different environmental conditions. Such bacteria in the gastrointestinal microbiome may have systemic interactions, resulting in certain consequences in modulating microbial performance within the host organism. 


\subsection{Alpha-Biodiversity Indices of the Chicken Cloaca Bacteriobiome}

Biodiversity indices integrate information about the communities, assemblages, guilds, etc., of living organisms into a compact form, and are thus helpful in comparing large arrays of metagenomic data. Interestingly, prebiotic supplementation accounted for notable portions (ca. $20-25 \%)$ of the actual $(p \leq 0.10)$ and potential $(p \leq 0.05)$ species richness variance, decreasing the richness in both male and females, although in the latter samples the change was much more drastic (more than 2-fold) and statistically significant. Our finding that in the antibiotic-receiving group the Berger-Parker index was 1.5 times higher in the male bacteriobiome as compared with the female one, which can be at least in part ascribed to some difference between the sexes prior to antibiotic treatment, which started at 1-3 days of age. On the contrary, pectin treatment resulted in a more structured and much less diverse bacteriobiome in hens. The finding that one third of the Berger-Parker index's variance was determined by the 'sex $\times$ prebiotic' interaction implicates hormones in the structuring of the chicken excreta bacteriobiome. Overall, compared with the $\alpha$-biodiversity indices of the gut bacteriobiome of chickens reported previously [50,61], in our study the Shannon and Chao- 1 indices were lower, although they were assessed using the same methodology. Our results did not allow us to draw an unequivocal conclusion about the relationship between the biodiversity of the gut microbiota and chickens' growth performance.

\subsection{Cloaca Bacteriobiome Diversity and Chickens' Production Performance}

The result that the addition of pectin into the drinking water increased the production performance of broiler chickens is not consistent with some earlier studies, in which there was no effect of different prebiotics on broiler growth [62]. Other studies reported positive effects on feed nutrients' digestibility when pectin was given at the starter phase, and decreased nutrient digestibility at the growth phase [63].

Our finding that prebiotic supplementation decreased feed consumption per unit of the chickens' living mass, thus increasing the profitability of chicken production by more than two times, suggests that the bacteria that increased in abundance most likely represented regular commensal strains, rather than harmful ones. No antibiotic in the pectin treatment, rather than the pectin per se at the rate applied, may have benefited some bacteria that could be pathogenic, e.g., Escherichia/Shigella, in our study.

Physiologically and microbiologically, it would be more meaningful to explore the effect of an antibiotic and a prebiotic in the repeated-measures design, i.e., sampling cloaca contents from one and the same bird to assess its bacteriobiome diversity. To obtain a better insight into the eco- and pathophysiology of bacteriobiome components, it might be worthwhile to analyze gut/fecal bacteriobiome changes in a longer-term dynamic study; however, such results would not be meaningful practically, as broiler production is a short-term process.

\subsection{General Comments}

Our finding that sex is implicated in modulating chickens' gut microbiome might explain the poor reproducibility of the effects of pre- and probiotics and the uncertainty about their technical viability [64]. Notably, recent reviews have stated that the taxonomic composition of the chicken gastrointestinal microbiota "is affected by different factors, such as the organ, the age of the animal, diet and the use of antimicrobials" [65] and "varies according to diverse factors such as diet, location, and age" [66] without even mentioning the effect of sex [67]. Admittedly, the research about the role of sex in shaping chicken gut microbiota composition is rather scarce, and the available reports either give no relevant information or describe results obtained using birds of one sex [68].

If we had used a control group, i.e., chickens receiving neither antibiotics nor prebiotics [65], our study would have been more comprehensive and interesting from the basic ecophysiological point of view, and therefore the absence of such a group can be regarded as a drawback. On the other hand, since industrial chicken production in Russia employs 
antibiotics as growth promoters, such information might not be of immediate significance for large-scale poultry facilities.

As pectin is one of the major plant cell wall components, to date the number of studies on the effect of pectin supplementation in the poultry diet is still limited in terms of the mechanisms and extent of the effect. In view of our results, the pectin addition effect may be obscured - and hence not very encouraging as a research direction to pursue-due to the male/female ratio of the chicken flock.

In our study, pectin was administered following the same regimen as in the antibioticreceiving chickens. Apparently, the pectin addition regimen can be appropriately adjusted based on the results of further, more detailed investigations. When designing such studies, one should take into consideration that pectin is probably the most complex macromolecule in nature, as it can be composed of as many as 17 different monosaccharides with more than 20 different linkages $[27,69]$, and thus its effect on gut microbiome diversity and function may depend on a specific structure.

\section{Conclusions}

Our study aimed at comparing the structure and composition of cloaca bacteriobiome, as estimated using 16S rRNA gene amplicon sequencing, in male and female broiler chickens receiving antibiotic or prebiotic (pectin) with their drinking water. The cloaca bacteriobiome was found to be drastically dominated by just two phyla (Firmicutes and Proteobacteria), represented by three classes (Clostridia, Bacilli and Gammaproteobacteria). The cloaca bacteriobiome of prebiotic-receiving chickens differed from the antibioticreceiving birds in the relative abundance of some OTUs. The better feed use efficiency and growth performance displayed by the pectin-receiving chickens implied their better health and corroborated the putative role of the altered bacteriobiome, although its ecophysiological and/or pathogenic importance could not be readily inferred. At this point, the studied prebiotic supplementation regime can hardly be recommended for large-scale industrial chicken production; however, the studied prebiotic (pectin) can and should be used in developing new pre-/symbiotic preparations and their supplementation regimes as alternatives to antibiotics for stimulating broiler chicken production.

The results of our study indicate the existence of sex-specific gut microbial diversity, suggesting the likely involvement of sex-specific (hormonal) mechanisms underlying the response of the gut microbiota to dietary supplementation. Therefore we strongly recommend targeting sex as a separate factor in interventional studies to account for sexspecific peculiarities in the microbiome's response, which can be useful for the development of sex-specific feed additives as separate sex rearing technologies are gaining popularity.

Author Contributions: Conceptualization, S.B.L. and V.I.P.; methodology, S.B.L.; software, M.R.K.; validation, O.A.B. and N.A.L.; formal analysis, O.A.B. and N.B.N.; investigation, O.A.B. and N.A.L.; resources, S.B.L. and V.I.P.; data curation, N.B.N.; writing—original draft preparation, S.B.L., O.A.B. and N.B.N.; writing—review and editing, N.A.L., M.R.K. and S.B.L.; visualization, O.A.B.; supervision, M.R.K.; project administration, S.B.L.; funding acquisition, V.I.P. and M.R.K. All authors have read and agreed to the published version of the manuscript.

Funding: This research was funded by the Ministry of Science and Higher Education of the Russian Federation [project number 075-15-2021-1085].

Institutional Review Board Statement: The study was conducted according to the guidelines of the Declaration of Helsinki, and approved by the Institutional Review Board of the Siberian Scientific Research Institute of Poultry Farming-Branch of the Federal State Budget Scientific Institution "Omsk Agrarian Scientific Center" (protocol No. 127 April 2020).

Informed Consent Statement: Not applicable.

Data Availability Statement: The read data reported in this study were submitted to GenBank under the study accession number PRJNA523560. 
Conflicts of Interest: The authors declare no conflict of interest. The funders had no role in the design of the study; in the collection, analyses, or interpretation of data; in the writing of the manuscript, or in the decision to publish the results.

\section{References}

1. FAO. FAOSTAT. Available online: http://www.fao.org/faostat/en/\#data/QA (accessed on 23 October 2021).

2. Manikandan, M.; Chun, S.; Kazibwe, Z.; Gopal, J.; Singh, U.B.; Oh, J.-W. Phenomenal Bombardment of Antibiotic in Poultry: Contemplating the Environmental Repercussions. Int. J. Environ. Res. Public Health 2020, 17, 5053. [CrossRef]

3. Kuppusamy, S.; Kakarla, D.; Venkateswarlu, K.; Megharaj, M.; Yoon, Y.-E.; Lee, Y.B. Veterinary antibiotics (VAs) contamination as a global agro-ecological issue: A critical view. Agric. Ecosyst. Environ. 2018, 257, 47-59. [CrossRef]

4. $\quad \mathrm{Wu}, \mathrm{S}$.; $\mathrm{Wu}, \mathrm{Y}$.; Huang, Q.; Cai, P. Insights into conjugative transfer of antibiotic resistance genes affected by soil minerals. Eur. J. Soil Sci. 2021, 72, 1143-1153. [CrossRef]

5. World Health Organization (WHO). Antimicrobial Resistance in the Food Chain. Available online: https://www.who.int/ foodsafety/areas_work/antimicrobial-resistance/amrfoodchain/en/ (accessed on 23 October 2021).

6. Iwu, C.D.; Korsten, L.; Okoh, A.I. The incidence of antibiotic resistance within and beyond the agricultural ecosystem: A concern for public health. MicrobiologyOpen 2020, 9, e1035. [CrossRef]

7. Borda-Molina, D.; Seifert, J.; Camarinha-Silva, A. Current perspectives of the chicken gastrointestinal tract and its microbiome. Comput. Struct. Biotechnol. J. 2018, 16, 131-139. [CrossRef] [PubMed]

8. Diaz Carrasco, J.M.; Casanova, N.A.; Fernández Miyakawa, M.E. Microbiota, Gut Health and Chicken Productivity: What Is the Connection? Microorganisms 2019, 7, 374. [CrossRef]

9. Oviedo-Rondón, E.O. Holistic view of intestinal health in poultry. Anim. Feed Sci. Technol. 2019, 250, 1-8. [CrossRef]

10. Shang, Y.; Kumar, S.; Oakley, B.; Kim, W.K. Chicken Gut Microbiota: Importance and Detection Technology. Front. Vet. Sci. 2018, 5, 254. [CrossRef] [PubMed]

11. Kogut, M.H. The effect of microbiome modulation on the intestinal health of poultry. Anim. Feed Sci. Technol. 2019, 250, 32-40. [CrossRef]

12. Yegani, M.; Korver, D.R. Factors affecting intestinal health in poultry. Poult. Sci. 2008, 87, 2052-2063. [CrossRef]

13. Rinttilä, T.; Apajalahti, J. Intestinal microbiota and metabolites-Implications for broiler chicken health and performance. J. Appl. Poult. Res. 2013, 22, 647-658. [CrossRef]

14. Franciosini, M.P.; Costarelli, S.; Cobellis, G.; Trabalza-Marinucci, M. Effects of dietary Lactobacillus acidophilus and Bacillus subtilis on laying performance, egg quality, blood biochemistry and immune response of organic laying hens. J. Anim. Physiol. Anim. Nutr. 2016, 100, 977-987. [CrossRef]

15. Mingmongkolchai, S.; Panbangred, W. Bacillus probiotics: An alternative to antibiotics for livestock production. J. Appl. Microbiol. 2018, 124, 1334-1346. [CrossRef] [PubMed]

16. Liu, X.; Liu, W.; Deng, Y.; He, C.; Xiao, B.; Guo, S.; Zhou, X.; Tang, S.; Qu, X. Use of encapsulated Bacillus subtilis and essential oils to improve antioxidant and immune status of blood and production and hatching performance of laying hens. Ital. J. Anim. Sci. 2020, 19, 1583-1591. [CrossRef]

17. Naumova, N.B.; Alikina, T.Y.; Zolotova, N.S.; Konev, A.V.; Pleshakova, V.I.; Lescheva, N.A.; Kabilov, M.R. Bacillus-based probiotic treatment modified bacteriobiome diversity in duck feces. Agriculture 2021, 11, 406. [CrossRef]

18. Shini, S.; Bryden, W.L. Probiotics and gut health: Linking gut homeostasis and poultry productivity. Anim. Prod. Sci. 2021, 12, 1-23. [CrossRef]

19. Teng, P.-Y.; Kim, W.K. Review: Roles of Prebiotics in Intestinal Ecosystem of Broilers. Front. Vet. Sci. 2018, 5, 245. [CrossRef] [PubMed]

20. Lillehoj, H.; Liu, Y.; Calsamiglia, S.; Fernandez-Miyakawa, M.E.; Chi, F.; Cravens, R.L.; Oh, S.; Gay, C.G. Phytochemicals as antibiotic alternatives to promote growth and enhance host health. Vet. Res. 2018, 49, 76. [CrossRef]

21. Iqbal, Y.; Cottrell, J.J.; Suleria, H.A.R.; Dunshea, F.R. Gut Microbiota-Polyphenol Interactions in Chicken: A Review. Animals 2020, 10, 1391. [CrossRef] [PubMed]

22. Śliżewska, K.; Markowiak-Kopeć, P.; Żbikowski, A.; Szeleszczuk, P. The effect of synbiotic preparations on the intestinal microbiota and her metabolism in broiler chickens. Sci. Rep. 2020, 10, 4281. [CrossRef]

23. Kers, J.G.; Velkers, F.C.; Fischer, E.; Hermes, G.; Stegeman, J.A.; Smidt, H. Host and Environmental Factors Affecting the Intestinal Microbiota in Chickens. Front. Microbiol. 2018, 9, 235. [CrossRef]

24. Gibson, G.R.; Roberfroid, M.B. Dietary modulation of the human colonic microbiota: Introducing the concept of prebiotics. J. Nutr. 1995, 125, 1401-1412. [CrossRef] [PubMed]

25. Ricke, S.C.; Lee, S.I.; Kim, S.A.; Park, S.H.; Shi, Z. Prebiotics and the poultry gastrointestinal tract microbiome. Poult. Sci. 2020, 99, 670-677. [CrossRef] [PubMed]

26. Voragen, A.G.J.; Coenen, G.J.; Verhoef, R.P.; Schols, H.A. Pectin, a versatile polysaccharide present in plant cell walls. Struct. Chem. 2009, 20, 263. [CrossRef]

27. Wang, S.; Xiao, Y.; Tian, F.; Zhao, J.; Zhang, H.; Zhai, Q.; Chen, W. Rational use of prebiotics for gut microbiota alterations: Specific bacterial phylotypes and related mechanisms. J. Funct. Foods 2020, 66, 103838. [CrossRef] 
28. Directive 2010/63/EU of the European Parliament and of the Council of 22 September 2010 on the Protection of Animals Used for Scientific Purposes. Available online: https:/ / data.europa.eu/eli/dir/2010/63/oj (accessed on 23 October 2021).

29. Dymkov, A.B.; Portyanko, A.V.; Lysko, S.B.; Zadorozhnaya, M.V.; Suntsova, O.A.; Shestakov, V.A.; Volokhova, L.P. The Method for Prophylaxis of Enteric Infections in Broiler Chickens. Patent 26602303 RF, 6 November 2015. (In Russian). Available online: https: / findpatent.ru/patent/260/2602303.html (accessed on 21 December 2021).

30. QIAGEN. Quick-Start Protocol. DNeasy PowerSoil Kit. 2016. Available online: https://www.qiagen.com/au/resources/ resourcedetail?id=3d576814-4f1e-4e26-9c94-57d5dc2bb60a\&lang=en (accessed on 21 December 2021).

31. Fadrosh, D.W.; Ma, B.; Gajer, P.; Gajer, P.; Sengamalay, N.; Ott, S.; Brotman, R.M.; Ravel, J. An improved dual-indexing approach for multiplexed 16S rRNA gene sequencing on the Illumina MiSeq platform. Microbiome 2014, 2, 6. [CrossRef] [PubMed]

32. Igolkina, A.A.; Grekhov, G.A.; Pershina, E.V.; Samosorova, G.G.; Leunova, V.M.; Semenov, A.N.; Baturina, O.A.; Kabilov, M.R.; Andronov, E.E. Identifying components of mixed and contaminated soil samples by detecting specific signatures of control $16 \mathrm{~S}$ rRNA libraries. Ecol. Ind. 2018, 94, 446-453. [CrossRef]

33. Edgar, R.C. UPARSE: Highly accurate OTU sequences from microbial amplicon reads. Nat. Methods 2013, 10, 996-998. [CrossRef]

34. Edgar, R.C. UNOISE2: Improved error-correction for Illumina 16S and ITS amplicon reads. bioRxiv 2016, 081257. [CrossRef]

35. Wang, Q.; Garrity, G.M.; Tiedje, J.M.; Cole, J.R. Naïve Bayesian Classifier for Rapid Assignment of rRNA Sequences into the New Bacterial Taxonomy. Appl. Environ. Microbiol. 2007, 73, 5261-5267. [CrossRef] [PubMed]

36. Hsieh, T.C.; Ma, K.H.; Chao, A. INEXT: An R package for rarefaction and extrapolation of species diversity (Hill numbers). Meth. Ecol. Evol. 2016, 7, 1451-1456. [CrossRef]

37. Hughes, J.B.; Hellmann, J.J. The Application of Rarefaction Techniques to Molecular Inventories of Microbial Diversity. Methods Enzymol. 2005, 397, 292-308. [CrossRef] [PubMed]

38. Xiao, Y.; Xiang, Y.; Zhou, W.; Chen, J.; Li, K.; Yang, H. Microbial community mapping in intestinal tract of broiler chicken. Poult. Sci. 2016, 96, 1387-1393. [CrossRef] [PubMed]

39. Huang, P.; Zhang, Y.; Xiao, K.; Jiang, F.; Wang, H.; Tang, D.; Liu, D.; Liu, B.; Liu, Y.; He, X.; et al. The chicken gut metagenome and the modulatory effects of plant-derived benzylisoquinoline alkaloids. Microbiome 2018, 6, 211. [CrossRef]

40. Gong, J.; Si, W.; Forster, R.J.; Huang, R.; Yu, H.; Yin, Y.; Yang, C.; Han, Y. 16s rRNA gene-based analysis of mucosa-associated bacterial community and phylogeny in the chicken gastrointestinal tracts: From crops to ceca. FEMS Microbiol. Ecol. 2007, 59, 147-157. [CrossRef]

41. Videnska, P.; Rahman, M.M.; Faldynova, M.; Babak, V.; Matulova, M.E.; Prukner-Radovcic, E.; Krizek, I.; Smole-Mozina, S.; Kovac, J.; Szmolka, A.; et al. Characterization of Egg Laying Hen and Broiler Fecal Microbiota in Poultry Farms in Croatia, Czech Republic, Hungary and Slovenia. PLoS ONE 2014, 9, e110076. [CrossRef]

42. Gaastra, W.; Kusters, J.G.; van Duijkeren, E.; Lipman, L.J.A. Escherichia fergusonii. Vet. Microbiol. 2014, 172, 7-12. [CrossRef]

43. Gilroy, R.; Ravi, A.; Getino, M.; Pursley, I.; Horton, D.L.; Alikhan, N.; Baker, D.; Gharbi, K.; Hall, N.; Watson, M.; et al. Extensive microbial diversity within the chicken gut microbiome revealed by metagenomics and culture. PeerJ 2021, 9, e10941. [CrossRef]

44. Lu, J.; Idris, U.; Harmon, B.; Hofacre, C.; Maurer, J.J.; Lee, M.D. Diversity and succession of the intestinal bacterial community of the maturing broiler chicken. Appl. Environ. Microbiol. 2003, 69, 6816-6824. [CrossRef]

45. Cao, G.T.; Zeng, X.F.; Chen, A.G.; Zhou, L.; Zhang, L.; Xiao, Y.P.; Yang, C.M. Effects of a probiotic, Enterococcus faecium, on growth performance, intestinal morphology, immune response, and cecal microflora in broiler chickens challenged with Escherichia coli K88. Poult. Sci. 2013, 92, 2949-2955. [CrossRef]

46. He, Y.; Liu, X.; Dong, Y.; Lei, J.; Ito, K.; Zhang, B. Enterococcus faecium PNC01 isolated from the intestinal mucosa of chicken as an alternative for antibiotics to reduce feed conversion rate in broiler chickens. Microb. Cell Fact. 2021, 20, 122. [CrossRef]

47. Stępień-Pyśniak, D.; Hauschild, T.; Dec, M.; Marek, A.; Urban-Chmiel, R.; Kosikowska, U. Phenotypic and genotypic characterization of Enterococcus spp. from yolk sac infections in broiler chicks with a focus on virulence factors. Poult. Sci. 2021, 100, 100985. [CrossRef] [PubMed]

48. Hankel, J.; Bodmann, B.; Todte, M.; Galvez, E.; Strowig, T.; Radko, D.; Antakli, A.; Visscher, C. Comparison of Chicken Cecal Microbiota after Metaphylactic Treatment or Following Administration of Feed Additives in a Broiler Farm with Enterococcal Spondylitis History. Pathogens 2021, 10, 1068. [CrossRef] [PubMed]

49. Borst, L.; Suyemoto, M.; Sarsour, A.; Harris, M.; Martin, M.; Strickland, J.; Oviedo, E.; Barnes, H. Pathogenesis of enterococcal spondylitis caused by Enterococcus cecorum in broiler chickens. Vet. Pathol. 2017, 54, 61-73. [CrossRef]

50. Kumar, S.; Chen, C.; Indugu, N.; Werlang, G.O.; Singh, M.; Kim, W.K.; Thippareddi, H. Effect of antibiotic withdrawal in feed on chicken gut microbial dynamics, immunity, growth performance and prevalence of foodborne pathogens. PLoS ONE 2018, 13, e0192450. [CrossRef]

51. Li, M.; Gu, C.; Zhang, W.; Li, S.; Liu, J.; Qin, C.; Su, J.; Cheng, G.; Hu, X. Isolation and characterization of Streptococcus gallolyticus subsp. pasteurianus causing meningitis in ducks. Vet. Microbiol. 2013, 162, 93036. [CrossRef] [PubMed]

52. Eeckhaut, V.; Wang, J.; van Parys, A.; Haesebrouck, F.; Joossens, M.; Falony, G.; Raes, J.; Ducatelle, R.; van Immerseel, F. The Probiotic Butyricicoccus pullicaecorum Reduces Feed Conversion and Protects from Potentially Harmful Intestinal Microorganisms and Necrotic Enteritis in Broilers. Front. Microbiol. 2016, 7, 1416. [CrossRef] [PubMed]

53. Vezina, B.; Allnutt, T.; Keyburn, A.L.; Wade, B.; Van, T.T.H.; Johanesen, P.; Lyras, D.; Moore, R.J. Stable recombinant-gene expression from a Ligilactobacillus live bacterial vector via chromosomal integration. Appl. Environ. Microbiol. 2021, 87, e00392-21. [CrossRef] [PubMed] 
54. Cooper, K.K.; Songer, J.G.; Uzal, F.A. Diagnosing clostridial enteric disease in poultry. J. Vet. Diagn. Investig. 2013, 25, 314-327. [CrossRef]

55. Duranti, S.; Longhi, G.; Ventura, M.; van Sinderen, D.; Turroni, F. Exploring the Ecology of Bifidobacteria and Their Genetic Adaptation to the Mammalian Gut. Microorganisms 2021, 9, 8. [CrossRef] [PubMed]

56. Mountzouris, K.C.; Palamidi, I.; Tsirtsikos, P.; Mohnl, M.; Schatzmayr, G.; Fegeros, K. Effect of dietary inclusion level of a multi-species probiotic on broiler performance and two biomarkers of their caecal ecology. Anim. Prod. Sci. 2015, 55, 484-493. [CrossRef]

57. Uzal, F.A.; Navarro, M.A.; Li, J.; Freedman, J.C.; Shrestha, A.; McClane, B. A Comparative pathogenesis of enteric clostridial infections in humans and animals. Anaerobe 2018, 53, 11-20. [CrossRef]

58. Liu, X.; Mao, B.; Gu, J.; Wu, J.; Cui, S.; Wang, G.; Zhao, J.; Zhang, H.; Chen, W. Blautia-a new functional genus with potential probiotic properties? Gut Microbes 2021, 13, 1-21. [CrossRef] [PubMed]

59. Valles, C.; Mailhe, M.; Ricaboni, D.; Armstrong, N.; Alibar, S.; Vitton, V.; Lagier, J.-C.; Raoult, D.; Tidjani Alou, M. Negativibacillus massiliensis gen. nov., sp. nov., a New Bacterial Genus Isolated from a Human Left Colon Sample. Microbiol. Res. 2021, $12,29-42$. [CrossRef]

60. Kim, C.C.; Healey, G.R.; Kelly, W.J.; Patchett, M.L.; Jordens, Z.; Tannock, G.W.; Sims, I.M.; Bell, T.J.; Hederley, D.; Henrissat, B.; et al. Genomic insights from Monoglobus pectinilyticus: A pectin-degrading specialist bacterium in the human colon. ISME J. 2019, 13, 1437-1456. [CrossRef] [PubMed]

61. Paul, S.S.; Chatterjee, R.N.; Raju, M.V.L.N.; Prakash, B.; Rama Rao, S.V.; Yadav, S.P.; Kannan, A. Gut Microbial Composition Differs Extensively among Indian Native Chicken Breeds Originated in Different Geographical Locations and a Commercial Broiler Line, but Breed-Specific, as Well as Across-Breed Core Microbiomes, Are Found. Microorganisms 2021, 9, 391. [CrossRef] [PubMed]

62. Al-Khalaifa, H.; Al-Nasser, A.; Al-Surayee, T.; Al-Kandari, S.; Al-Enzi, N.; Al-Sharrah, T.; Ragheb, G.; Al-Qalaf, S.; Mohammed, A. Effect of dietary probiotics and prebiotics on the performance of broiler chickens. Poult. Sci. 2021, 100, 1329. [CrossRef]

63. Silva, V.K.; de Souza Morita, V.; Boleli, I.C. Effect of pectin extracted from citrus pulp on digesta characteristics and nutrient digestibility in broilers chickens. R. Bras. Zootec. 2013, 42, 575-583. [CrossRef]

64. Gilroy, R. Spotlight on the avian gut microbiome: Fresh opportunities in discovery. Avian Pathol. 2021, 50, 291-294. [CrossRef]

65. Clavijo, V.; Flórez, M.J.V. The gastrointestinal microbiome and its association with the control of pathogens in broiler chicken production: A review. Poult. Sci. 2018, 97, 1006-1021. [CrossRef]

66. Rubio, L.A. Possibilities of early life programming in broiler chickens via intestinal microbiota modulation. Poult. Sci. 2019, 98, 695-706. [CrossRef] [PubMed]

67. Pin Viso, N.; Redondo, E.; Díaz Carrasco, J.M.; Redondo, L.; Sabio Garcia, J.; Fernández Miyakawa, M.; Farber, M.D. Geography as non-genetic modulation factor of chicken cecal microbiota. PLoS ONE 2021, 16, e0244724. [CrossRef] [PubMed]

68. Dai, D.; Qiu, K.; Zhang, H.J.; Wu, S.G.; Han, Y.M.; Wu, Y.Y.; Qi, G.H.; Wang, J. Organic Acids as Alternatives for Antibiotic Growth Promoters Alter the Intestinal Structure and Microbiota and Improve the Growth Performance in Broilers. Front. Microbiol. 2021, 11, 618144. [CrossRef] [PubMed]

69. O'Neill, M.A.; Ishii, T.; Albersheim, P.; Darvill, A.G. (RHAMNOGALACTURONAN II: Structure and Function of a Borate Cross-Linked Cell Wall Pectic Polysaccharide. Annu. Rev. Plant. Biol. 2004, 55, 109. [CrossRef] [PubMed] 